\title{
Intelligent based Multi-Agent Approach for University Timetable Scheduling System
}

\author{
Nicholas Oluwole Ogini \\ Department of Computer Science, \\ Delta State University, Abraka \\ Nigeria
}

\author{
Noah Oghenefego Ogwara \\ Department of Computer Science, \\ Delta State University, Abraka \\ Nigeria
}

\author{
Obeten Obi Ekabua \\ Department of Computer Science, \\ Delta State University, Abraka \\ Nigeria
}

\begin{abstract}
Consequently, in this paper, timetabling problem usually leads to conflicts of interest and requires both compromise and cooperation from the participant involved to solve this problem. The proposed system uses three agents: agent 1,2 and 3 to negotiate the scheduling of courses for both lecture and examination time table. Each agent negotiates for resources according to class size and venue capacity during time tabling generation. This combinatorial problem is both NP-hard and NP-Complete. Previous researches concentrates in solving the problem using genetic algorithm (GA), Artificial Intelligence (AI) and meta-heuristic. The solutions provided are domain specific and the approach adopted in this paper, is through the use of intelligent based multi-agent system which satisfies both hard and soft constraints by improving the time and space efficiency. The system implementation uses Visual BASIC.net by adopting the object oriented analysis and design methodology approach.
\end{abstract}

\section{Keywords}

Intelligent system, time efficiency, multi agents, timetable scheduling, NP-Hard Problem, NP-Hard Complete.

\section{INTRODUCTION}

Recently, timetabling scheduling have drawn a lots of attention because of its importance in everyday life, researchers have proposed different solutions in order to provide an optimal solutions to this problem. Timetabling problem can also be refers to as NP-Complete problem because of the personal scheduling problem which is also known [1]. However, several techniques have been applied to solve timetabling problem in the different sectors across the world. Some of these techniques apply the concept of artificial intelligence (AI) in solving time tabling problems. Solving timetabling scheduling problem usually requires a lot of time and effort in order to generate a reliable and efficient timetable for use in the university. The participant involves in the timetabling scheduling system usually have conflicting interest in real world application, which hence pose a greater challenge in an attempt to provides an optimal solution for NP-hard problem. In order to solve these problems of conflicts of interest, it is generally requires a compromise and cooperation from the participant involved. Although some preferences are usually given to participant with a higher rank in the educational system as compare to that of lower rank. These problems are related to preferences, availability and rank of the participant involved. [2]

More so, solution to many real-world problem and application stern-up from combinatorial problem (NP-hard, NP complete or Heuristics). Resolving the general task of timetable scheduling problem could be cumbersome and time consuming since the participants to the timetable scheduling could possibly have conflicting preferences, making the search for optimal solution an NP-hard problem. Sometimes, resolving these conflicting preferences requires compromise. However, in higher institutions, there are no intelligent time table systems. In practice majority of educational institutions in the world are using the manual system in generating time table. In order to solve this problem of timetabling scheduling in the university system this paper proposed multi-agent techniques in generating university lecture and examination time table [3].

\section{REVIEW OF RELATED WORKS}

This section presents some related works:

[1] Design a multi-agent model for timetabling problem which uses a cooperative agent to manage all possible constraints in the time table generation process and provides an efficient means of communication among other agents. Their model was evaluated and the results of the evaluation shows an improve performance in producing an efficient time table.

[2]develops a multi-agent system for university course time tabling scheduling which uses a distributed and dynamic environment for efficient timetabling scheduling. The model presented in her work uses interaction diagrams and consider all restrictions during timetabling scheduling.

[3] design a multi-agent system for university course time timetabling which uses two agents (course and signboard agents) each of this agents were responsible for course allocation and negotiation of courses to be allocated to specific venue at a particular point in time that leads to a highly intelligent and flexible timetable system.

\section{THE EXISTING SYSTEM}

In the university, the current system used in time tabling scheduling is the manual techniques where the time table officer and their committee draw out the time table at the commencement of every semester. Although various challenges are associated with this approach where student complain of clashes, where the same venue are allocated to the different courses at the same time. In addition, most of lecturer courses clashes such that a lecturer might be having two lectures at the same time in different venues. However as results of these conflicts in the timetable system, most departments usually have more than one version of the same timetable after correction due to the issue raised by the lecturer or student. In this paper, the authors applied a multiagent approach to time tabling scheduling. 


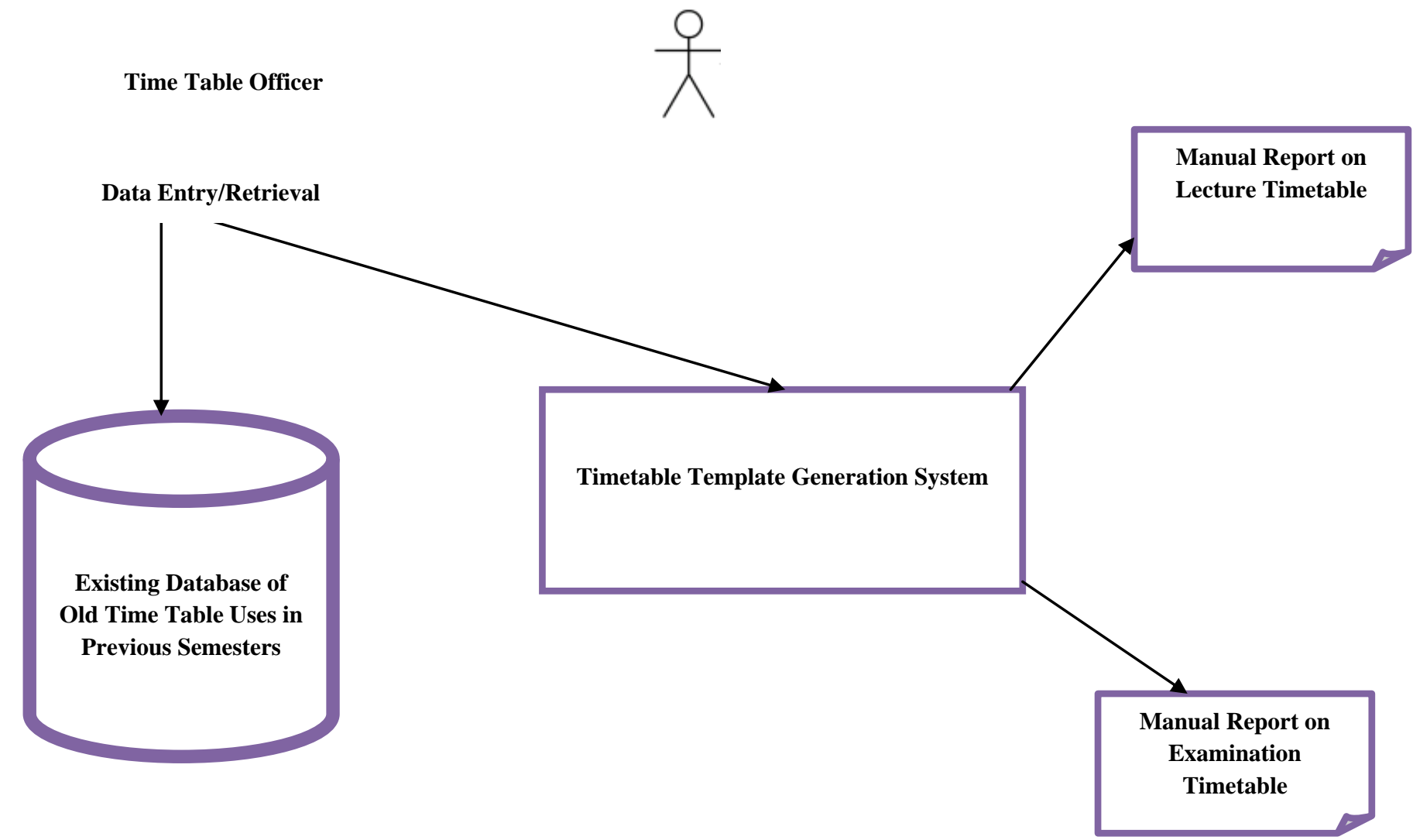

Figure 1 Existing Time Table Generation System

\subsection{Problems of the Existing System}

Information gathered from the existing system shows that the system has the following challenges.

* Lecturers have two different course at the same time

* Different Lectures been schedules on the same venue

* Time Consumption

* Lecture Instability due to various clashes in the time table

* Poor Time table structure

* Waste of human efforts

* Allocation of Student to Venue that are lower than the numbers of student that are writing that course in an examination

\subsection{Hard and Soft constraints of the}

\section{Timetable system}

In this paper, the hard constraints must be satisfied, because a breach of these constraints may results to incomplete solution to the timetable problem. The following are the hard constraints consider in this paper

* Two lectures cannot be hold in the same venue and at the same period of time.

* The lectures allocated to the same lecturer cannot take place at the same time on a particular day.
* A venue can only be assigned to one lecture at the same period of time.

* The number of students must not exceed the capacity of the assigned lecture venue.

* Two departmental courses offer at the same level cannot be assigned for examination on the same examination day.

The soft constraints are usually not compulsory to satisfy all conditions during timetable generation. The breach of these constraints does not affect the timetable generated

* The assignment of venues and periods of time must satisfy at best the preferences of the lecturer involved based on their rank.

* The assignment of venues to the different lectures must satisfy at best some preferences.

\section{THE PROPOSED SYSTEM}

In this paper, the authors proposed an intelligent- based time tabling scheduling system for lecture and examination time table using a multi-agent approach.

\subsection{System Architecture}

The system comprises of three agents namely Agent 1, Agent 2 and Agent 3. These agents are communicating with each other in order to produce an efficient time table for both lectures and examination. Figure 2 shows the architectural diagram of the proposed system. 


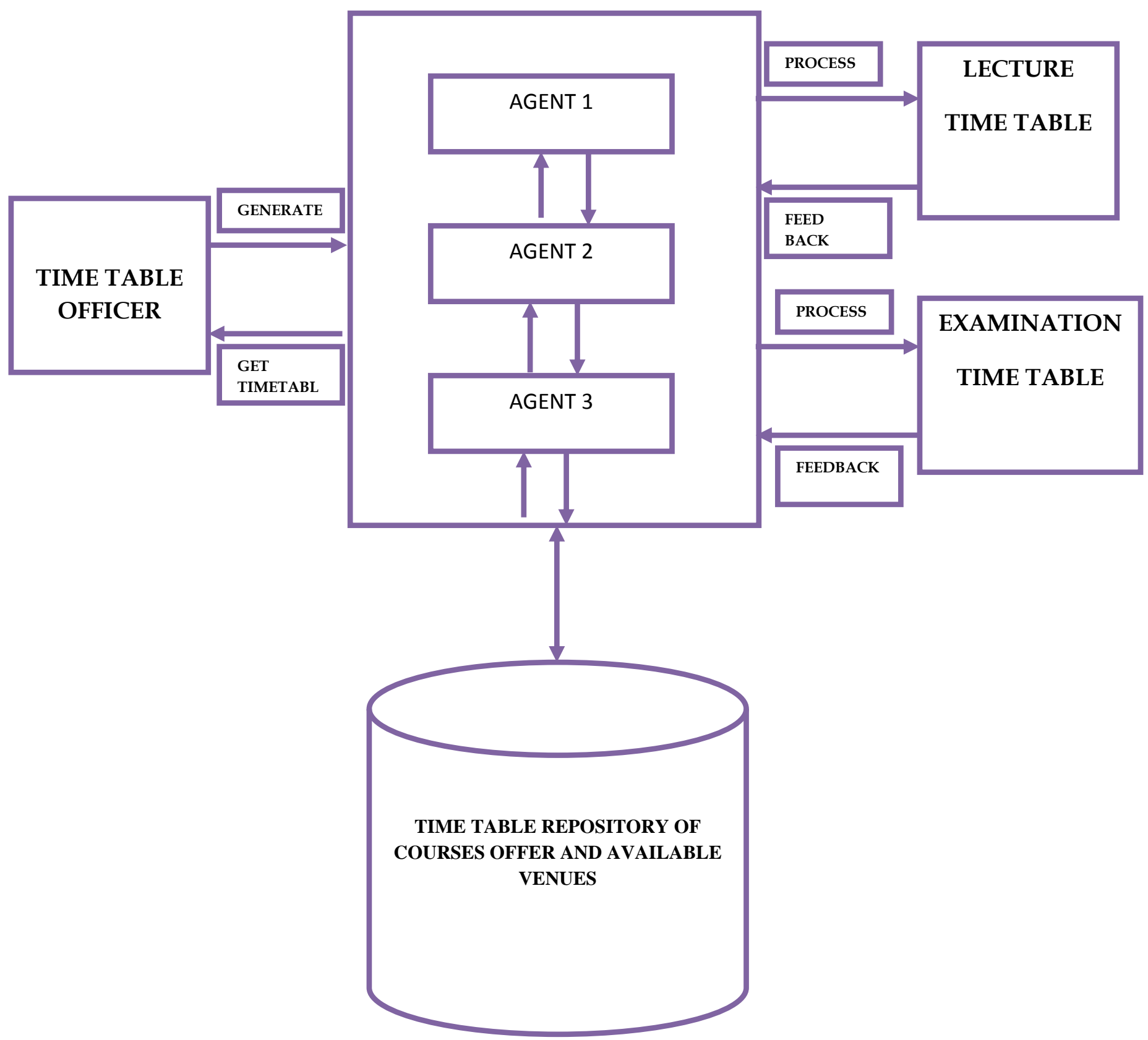

Figure 2 Architecture Diagram of the Multi-agent Time Tabling Scheduling System

(i) Agent 1: This agent is responsible for data capture from the university time table officer. The timetable officer is expected to upload information of all courses and venues. Each course data is expected to capture the title of the course and the estimated student that likely to take the course. The status of the course is also expected from this agent in order to categorize the course as either a university wide course, faculty based course or departmental based course. In the case of faculty, the list of possible faculty offering the course is also capture by this agent. Venue information is expected to state the capacity of each venue, at the end of this process agent 1 process and store this information in a central database. This agent has sub agents and a middle man agent. The job of the middle man agent is to resolve all conflicts among the sub agents and communicate their resolution to agent 1. Each sub agent is responsible to manage the activities of each department time table officer whose duty is to upload course allocation on semester basis. Agent 1 has the ability to send request to all sub agents to submit list of possible venues for each course. The sub agents negotiate among each other and the results of their resolution is communicated to the middle man agent whose in turn communicates this information to agent 1 .

(ii) Agent 2: This agent is responsible to manage lecturer's preferences. The agent assigns priority to professor and other high ranking staffs. Each high ranking staff is expected to communicate the likely day and time she will prefer their lecture or examination to hold. In this regards, all preferences are treated based on the rank of the staff. Top most priority are assign to professors, once all this information are supply by various staffs, the agent responsibility is to resolve possible conflicts and communicate the staffs on the changes based on 
the resolution of the conflicts having satisfy all the requirements for an efficient generation of the time table. This agent has the ability to fix a particular course on particular day and time on the time table. All such fixed requests are treated first during the generation of the time table, before processing the preferences resolved by this agent after resolving with the participant concerned.

(iii) Agent 3: This agent is responsible to manage all conflicts regarding when a course should be taken. This agent also communicates with agent 1 middle man agents to collate information about the resolve time and likely venues to fix a course on the time table. This agent is also responsible to collect information about the days and the number of periods to be used in the generation of lecture time table. In the case of examination time table generation this agents communicate with agent 1 to get information about when examination will start and when it will end so that the agent can uses to plan the allocation of courses to venue and time on the time table.

\subsection{High Level Model}

Figure 3 shows the high level model of the new system: The system is divided into three modules: Admin module, Multiagent module and Time Table Schedule module.

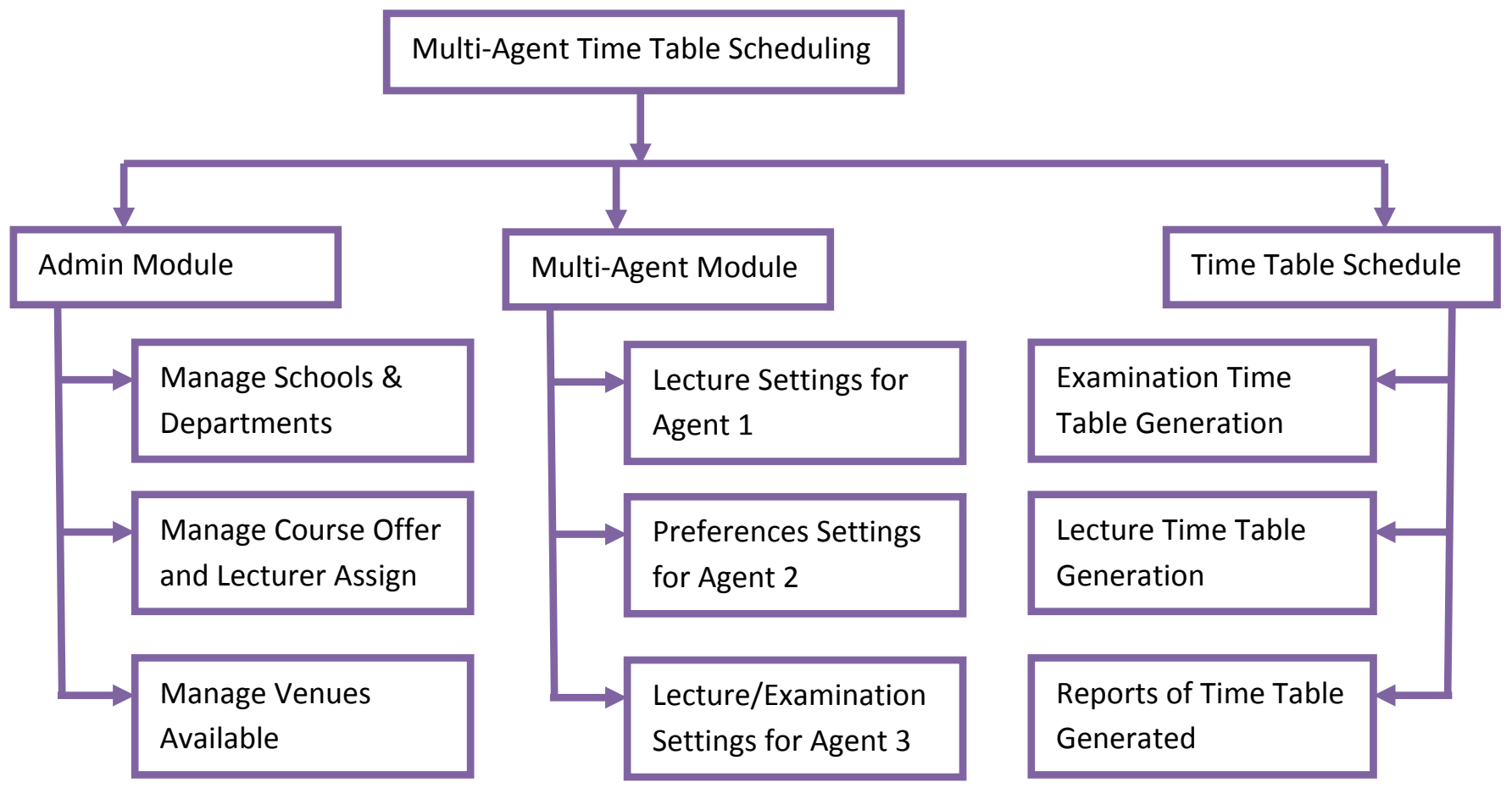

Figure 3 High Level Model of the Multi-agent Time Tabling Scheduling System

\subsection{Use Case Diagram}

Figure 4 show the user interaction with system using a unified modeling language diagrams. 


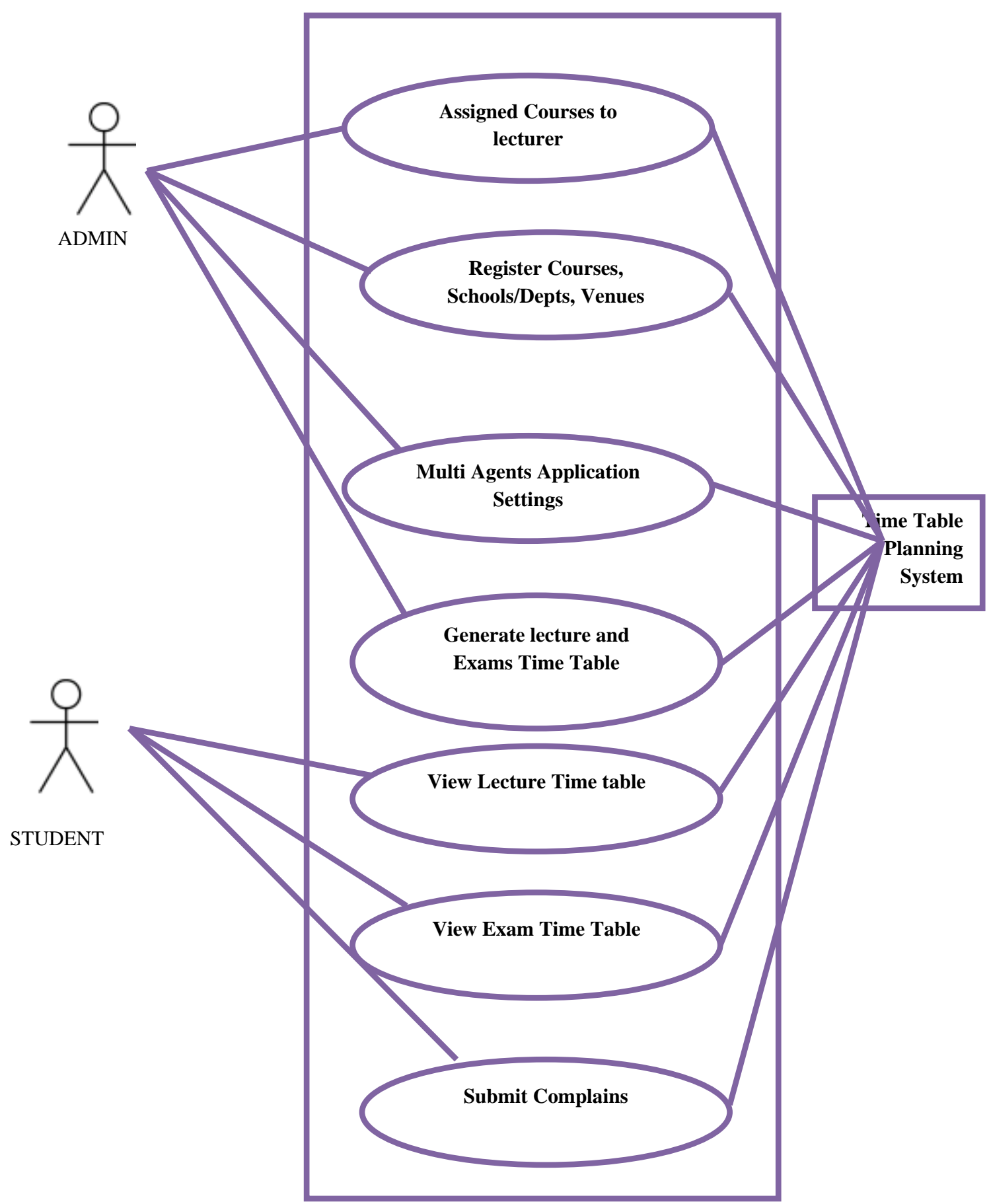

Figure 4 Use Case Diagram for Multi-agent Time Tabling Scheduling System 


\subsection{Overall Program Flow Chart}

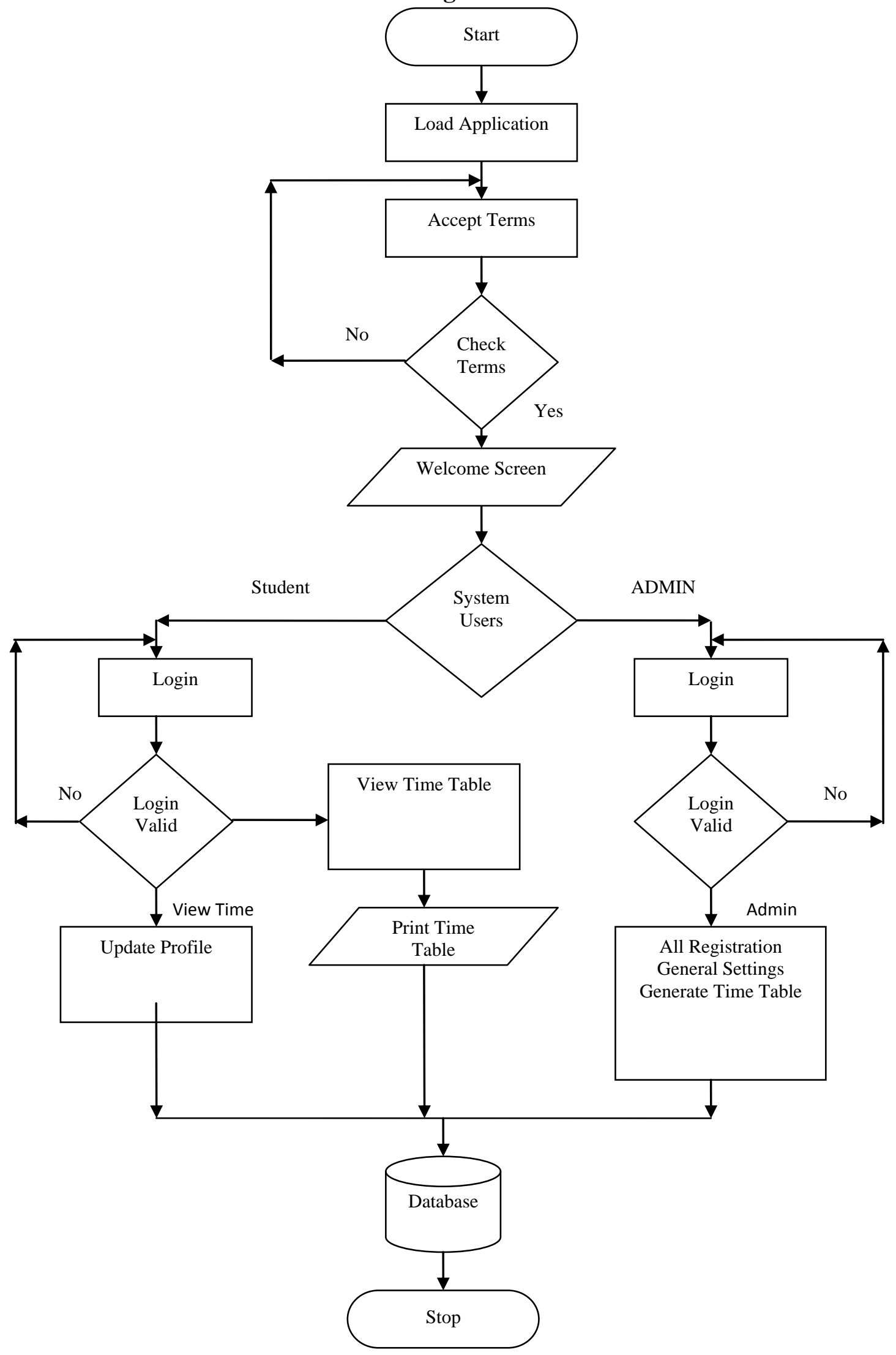

Figure 5. Overall Program Flowchart 


\section{RESULTS AND DISCUSSIONS}

In this paper, the authors implemented an intelligent based time tabling scheduling system using multi-agent approach. The system was design using Microsoft Visual Studio 2010 as the integrated development environment; Microsoft SQL Server 2012 was used as the database server and Visual Basic as the language of implementation. This paper adopted the Object oriented design methodology as the software methodology in the course of this work. The resulted system shows an improve performance over existing system. The

Main Menu Form: It shows the various modules of the entire system

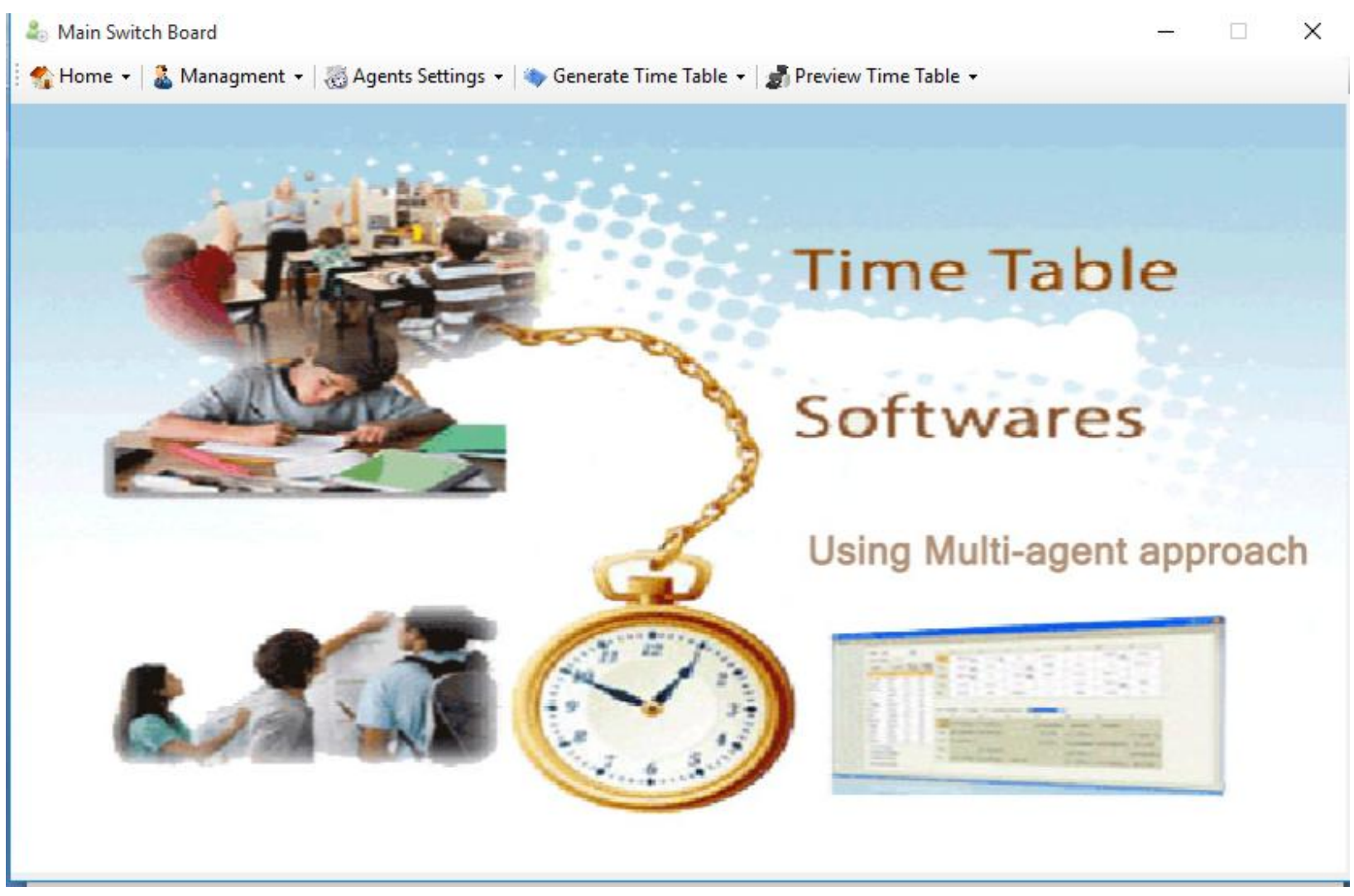

Figure 6 Main Switchboard

New Faculty: This form enables the system admin to add various faculties that are in the university that intends to use the time table planning system.

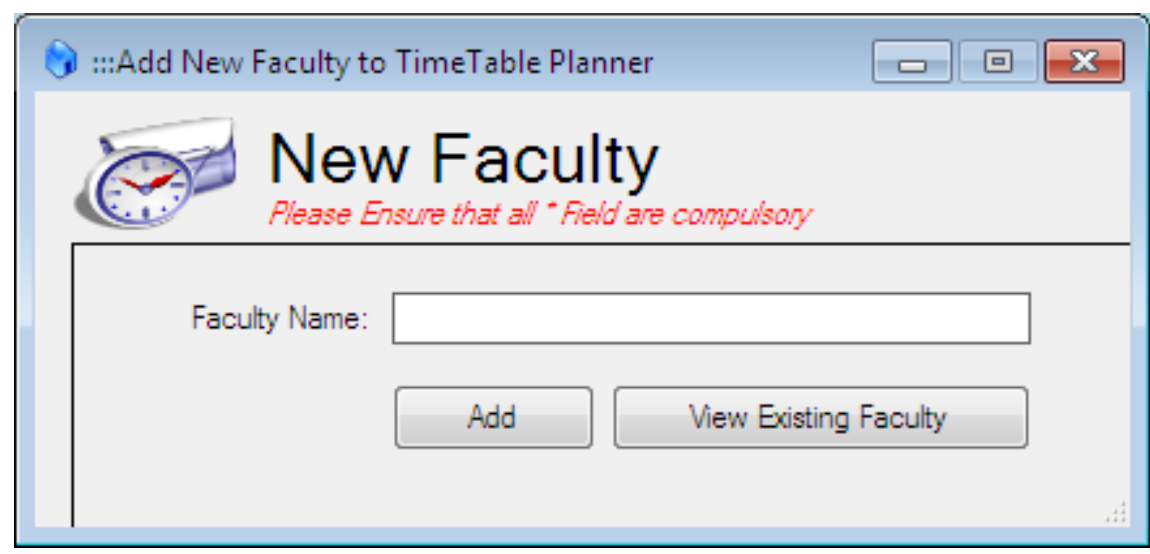

Figure 7 New Faculty Registrations time it takes to generates time table was less than 4 minutes in generating an entire university time table as compared to other system that spends more than 10 minutes in generating such time table. This improvement was as a result of the intelligent nature, effective communication and cooperation of all the various agents which helps in generating a reliable and efficient time table satisfying both hard and soft constraint as in [1]. Below are some of the inputs and output design of the new system.

\section{the time table planing system.}


New Department: This Form allow one to add Departments to the system

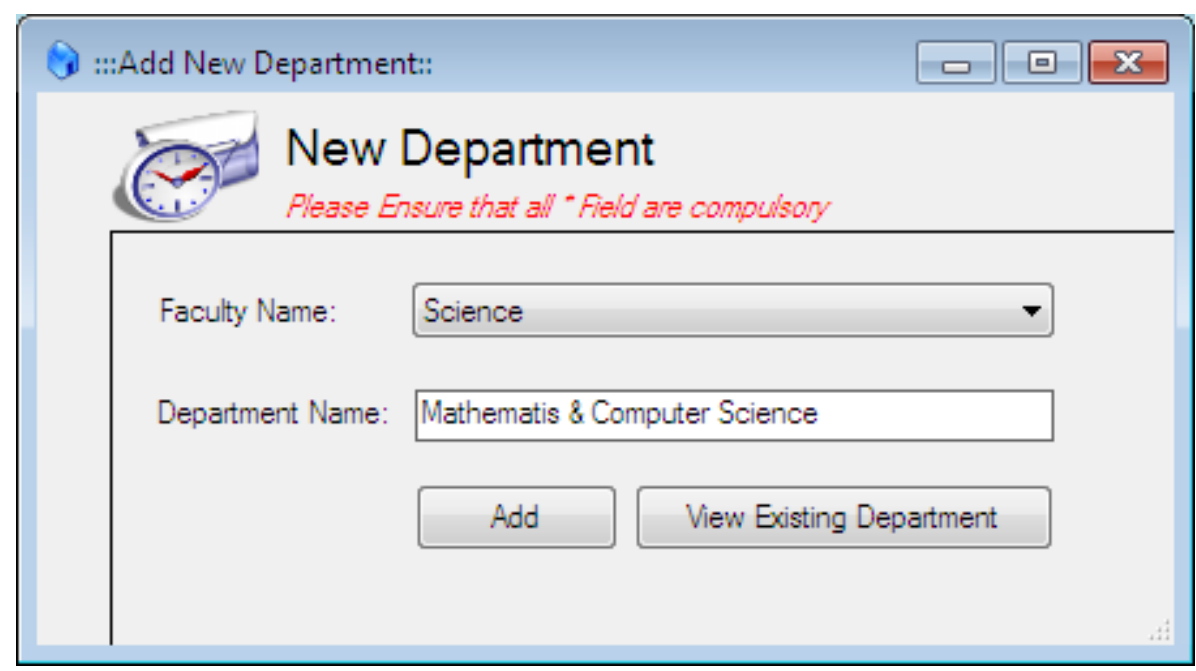

Figure 8 New Department Registrations

Venues: This form enables the system administrator to add venues to the Database

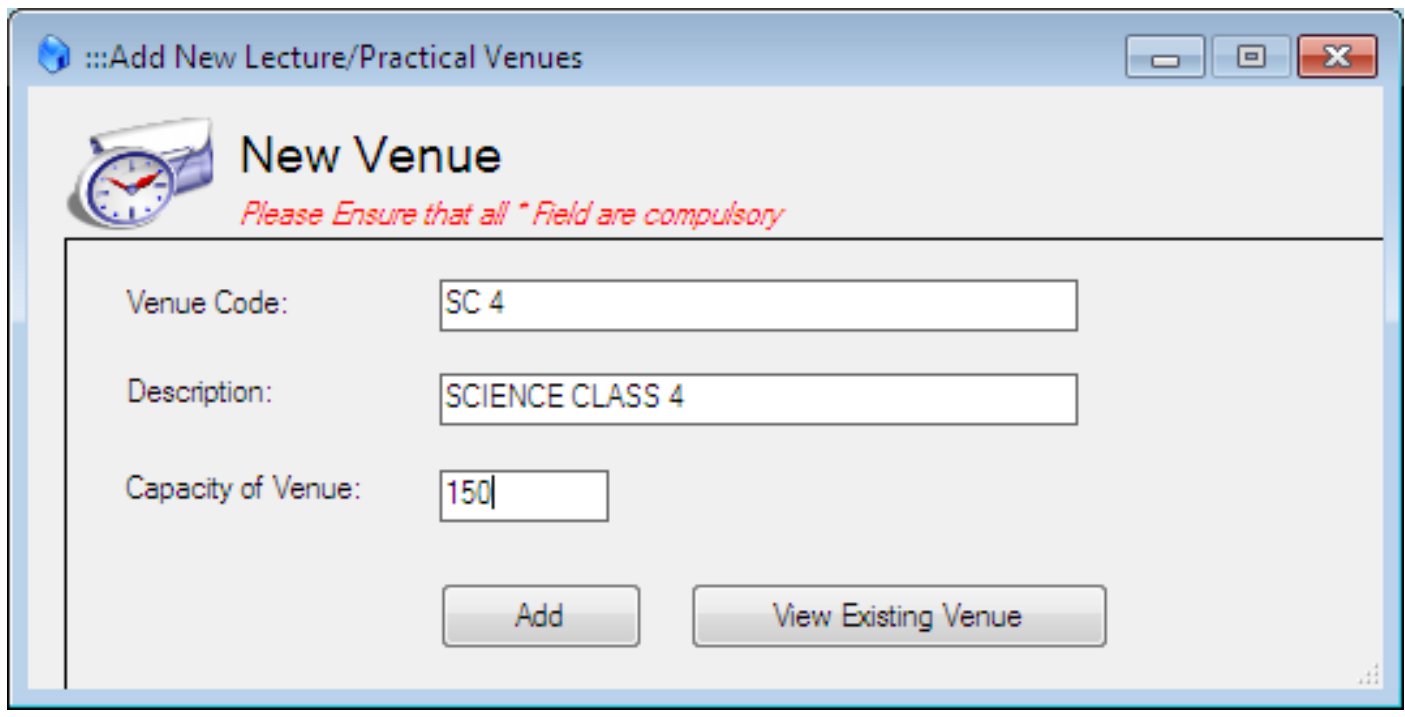

Figure 9 New Venue Registrations

New Course: This Form allows the system users to register all the course with the various lecturer and their proposed venues so that when the system generated the timetable it will assigned such course to the proposed venues 


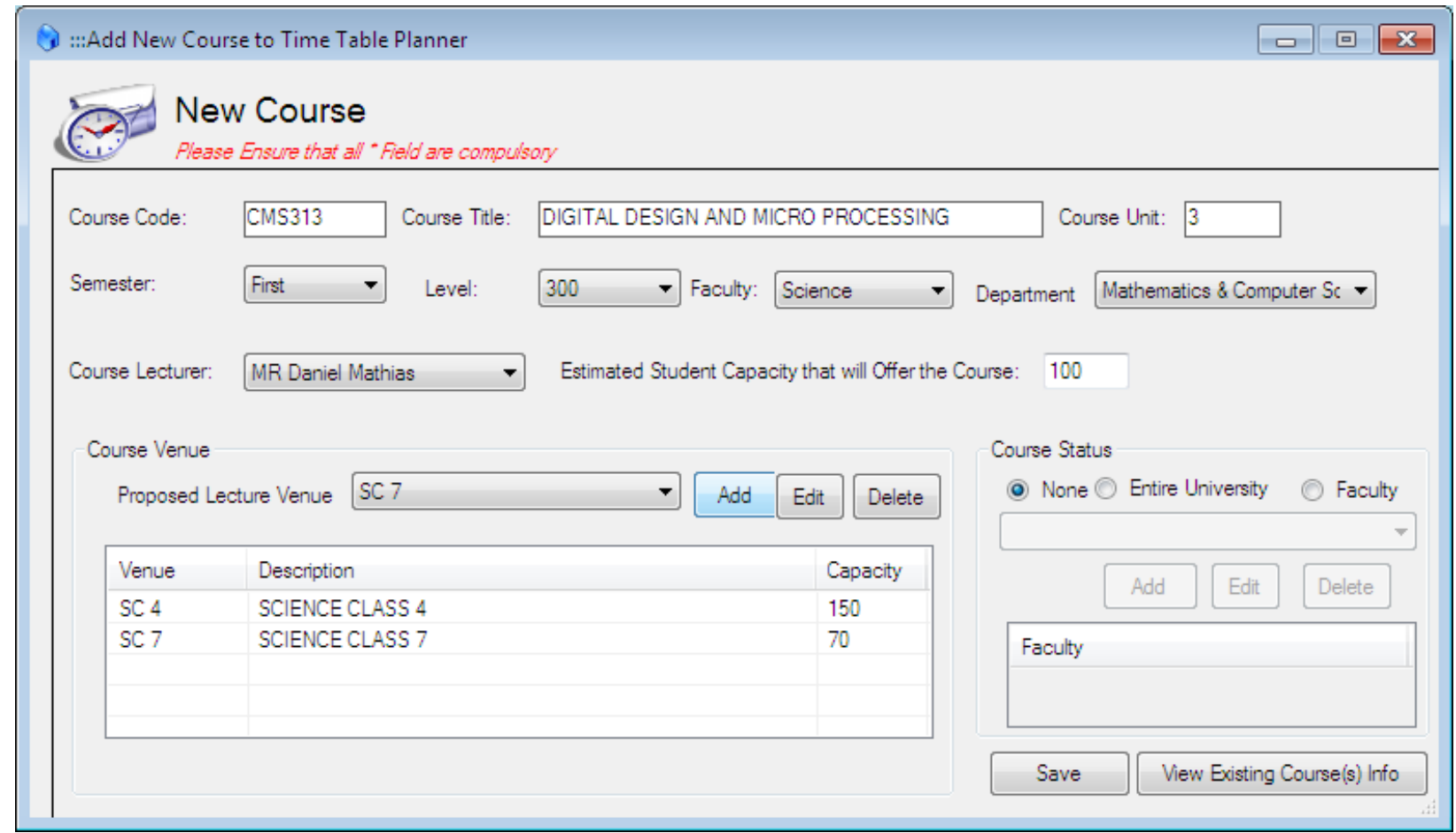

Figure 10 New Course Offer Registrations

New Lecturer: This form allow users to add course lecturer to the database for the purpose of time table generation

No ::Add New Lecturer:::
Name of Lecturer: MR Daniel Mathias
Department Name: Mathematics \& Computer Science

\section{Figure 11 New Lecturer Information Registration}

Lecture Settings Form: This form allow the system users to do some settings for lecture which will be use as a basis for lecture time table generation, such as the various lecture periods, Lecture days and so on.

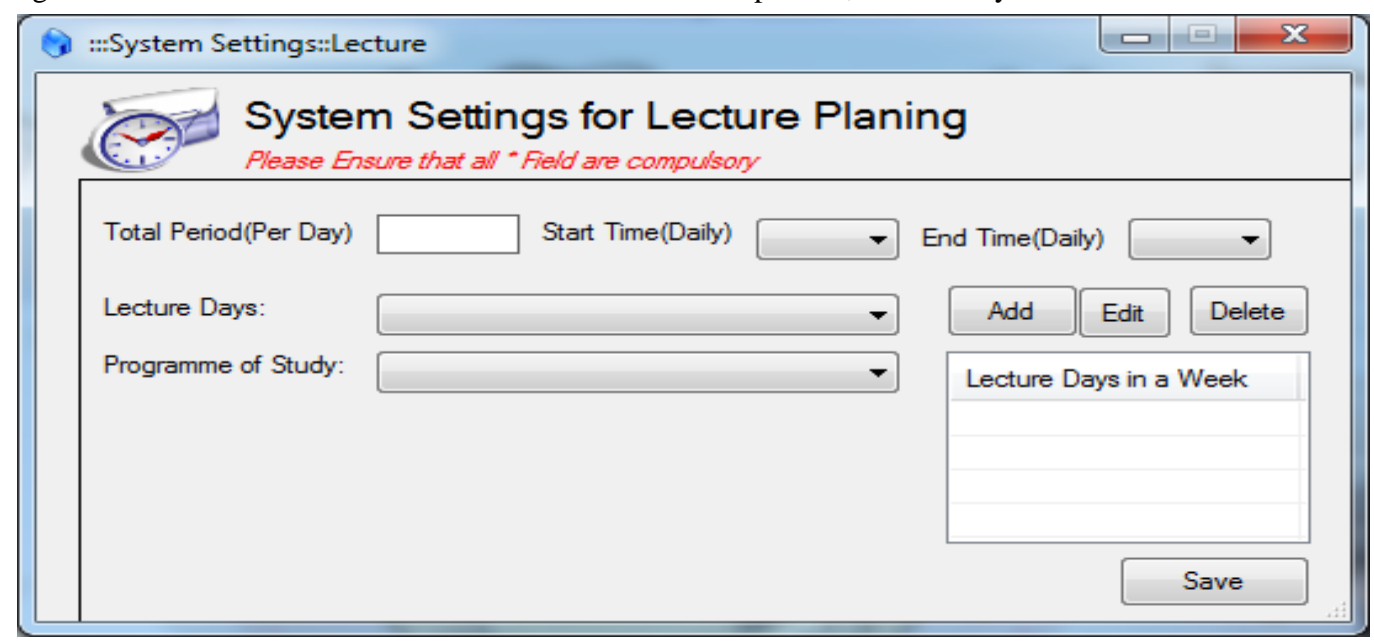

Figure 12 Lecture Settings Registration 
Examination Schedule: This form allow the users to define examination date when it start and when it will ends so that the system can used those information to generated time table for examination purpose.

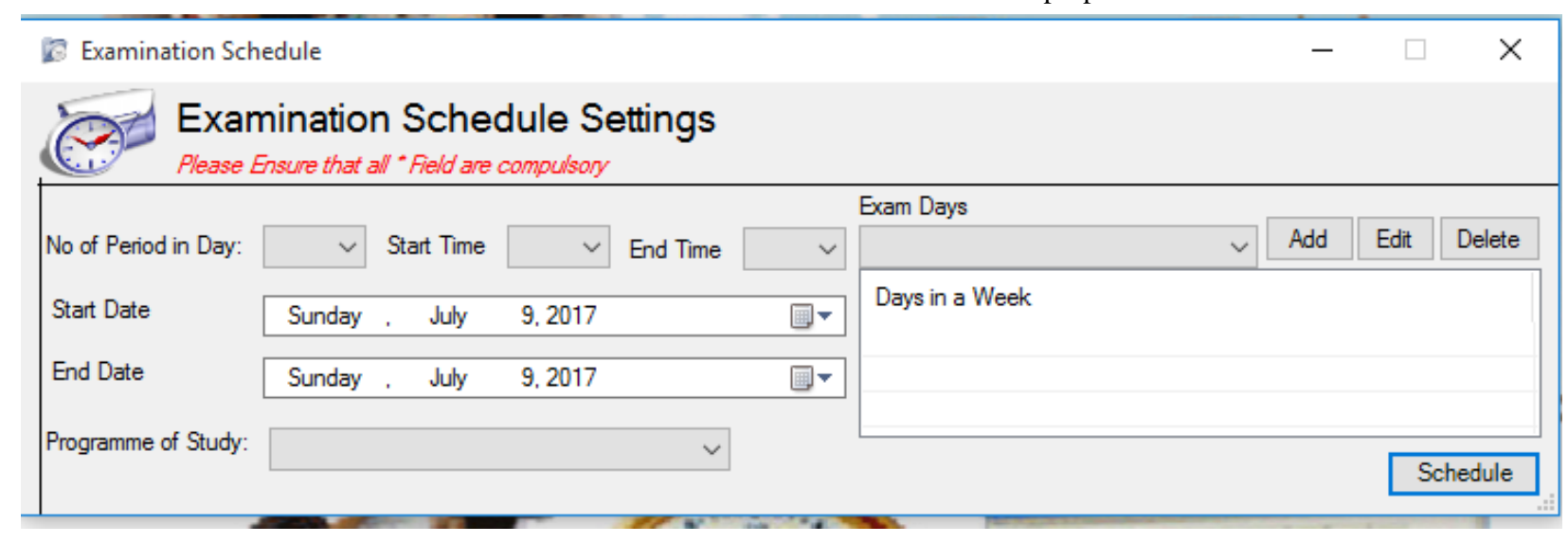

Figure 13 Examination Schedule

Lecture Preferences Settings for Lectures: This form allow users to set preference for some courses, lecturer on when their lecture will be assigned to

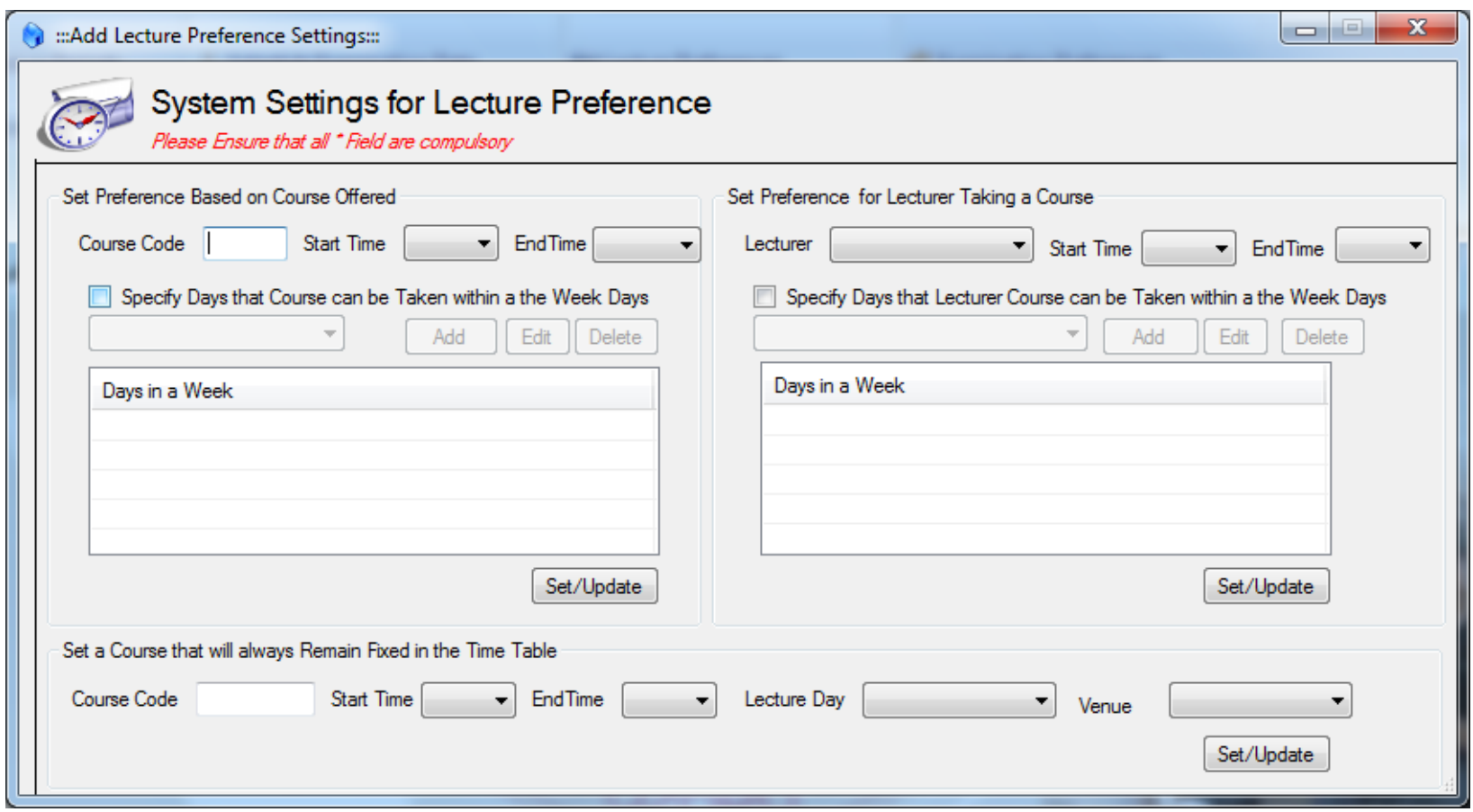

Figure 14 Agent Lecture Preferences Settings

Examination Time table Generator: This form allows Users to generate Time table for examination base on system for the entire university. 
Generate Examination TimeTable

\section{Generate Examination Time Table}

Please Ensure that all "Field are compulsory

General

Semester

Generate Time Table

Preview Existing Time Table

Figure 15 Examination Time Table Generations

Sample Lecture Time Table generated from the system.

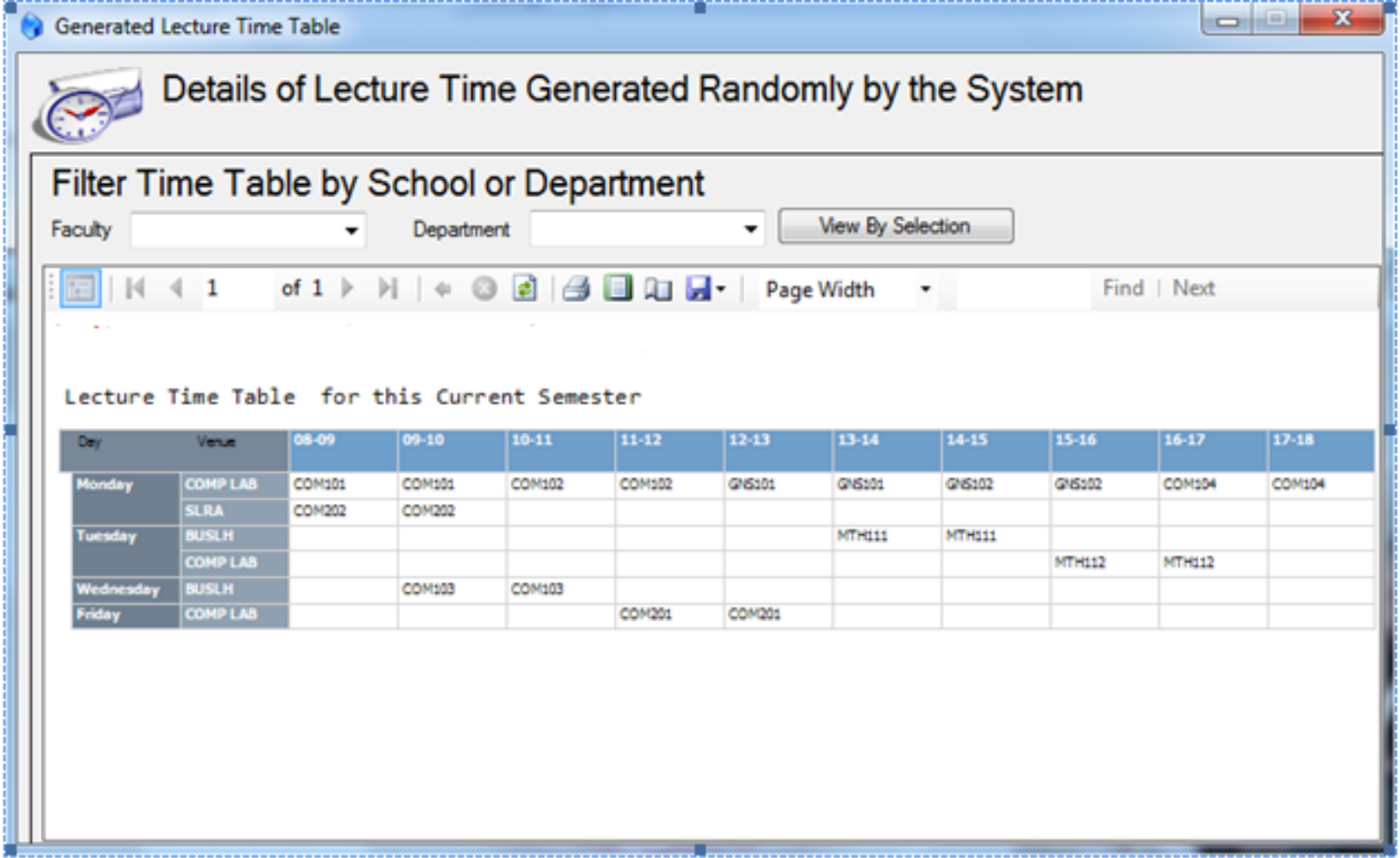

Figure 16 Lecture Time Table

\section{CONCLUSION}

In recent times, researchers have made a number of efforts towards the design and development of an intelligent system for educational sectors, but few of this system exist for the development of time table. This proposed intelligent based system for time table scheduling using a multi-agent approach is a step forward in solving the time table problem being an NP-hard problem. This paper presented three agents namely agent 1, agent 2 and agent 3 which allows communication and negotiation among them in order to generate an efficient time table system for university course. For further study different Artificial intelligence methodology can be adopted alongside mobile agents in order to have a better system.

\section{REFERENCES}

[1] Nouri H. E. and Driss O. B. 2013. Distributed model for university course timetabling problem, International Conference on Computer Applications Technology (ICCAT), Sousse, pp. 1-6.
[2] Oprea M. 2007. MAS_UP_UCT: A Multi- Agent System for University Course Timetable Scheduling, International Journal of Computers, Communications and Control. Vol. 2, No. 1, pp. 94-102.

[3]Yang Y, Paranjape R, Benedicenti L, and Reed N. 2011.A Multi Agent System for Course Timetabling. Journal of Intelligent Decision Technologies, vol. 5, no. 2, pp. 113131.

[4] Nikolaj C.2008. On some drawbacks of the PHP platform In Proc. of the 9th International Conference on Computer Systems and Technologies and Workshop for $\mathrm{PhD}$ Students in Computing.

[5] Antonio B, Matt C, Cao B.2002. Adding subqueries to MySQL, what does it take to have a decision-support engine? In Proceedings of the 5th ACM international workshop on Data Warehousing and OLAP,pages.49-56. 
[6]Yue H.W. 2009. Characterizing Insecure JavaScript Practices on the Web In Proc. 18th International Conference on World Wide Web, Madrid, pages 961970 .
[7] Takeshi T and Megumi T.2006. Production of the time table management system of commercial course university. In Proc. World Conference on E-Learning in Corporate, Government, Healthcare, \& Higher Education, 30, pages 48-3052. 